\title{
Special issue on gas-phase molecular spectroscopy dedicated to 75th birth anniversary of Professor Mihir Chowdhury
}

\author{
Published online: 24 April 2012
}

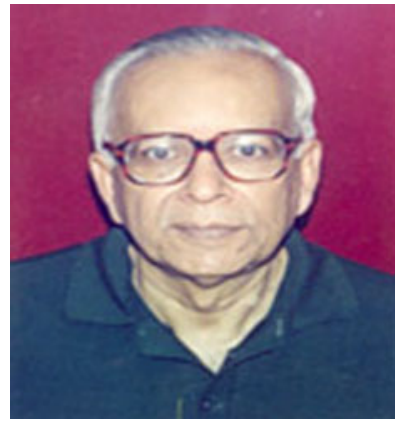

Year of Birth: 1937

This special thematic issue of the Indian Journal of Physics is dedicated to Professor Mihir Chowdhury on the occasion of his 75th birth anniversary. Professor Chowdhury is one of the finest spectroscopists in the post-Raman era of India, and an outstanding mentor to his undergraduate and Ph.D. students. His interests in physical chemistry and molecular spectroscopy in particular are both pervasive and diverse, ranging from characterizing the finer splitting of the energy levels of rare earth ions in crystals to magnetic field effect on photochemical reactions in liquids. He is one of the most complete spectroscopists produced by India, who is equally at ease with theoretical tools, and has used appropriate theoretical modeling when it was warranted. He put utmost efforts in building apparatus and initiating novel experiments. It was always a pleasure to experience the way he attempted and encouraged to answer inherently complex questions of fundamental importance through simple experiments and intuitive analyses. His students and associates were fortunate for being inspired continually by his unbridled passion for science and scientific discovery. As a human being, he is a gentleman par excellence, polite to a fault, exuding courage, dignity, character and vision. Laser spectroscopy in the gas-phase and molecular beams was the last venture in five decades of his scientific career, and this thematic issue on gas-phase molecular spectroscopy in IJP, authored by workers who have been stimulated by his leadership in the field, is dedicated as tribute to this extraordinary scientist. Owing to limitation in space of this issue of the journal, we regret for being unable to incorporate articles of others areas of his interests. The colleagues and students of his institute (D. Mukherjee, S. P. Bhattacharyya, D. S. Ray, K. Bhattacharyya, D. N. Nath and S. Adhikari) join the editor in wishing him a long life.

T Chakraborty Guest Editor Department of Physical Chemistry, Indian Association for the Cultivation of Science,

Calcutta, India 